\title{
A STUDY OF UPGRADED PHENOLIC CURING FOR RSRM NOZZLE RINGS
}

\author{
ZIBA SMARTT \\ Thiokol Propulsion, \\ Science and Engineering Huntsville Operations, Huntsville, AL
}

\begin{abstract}
A thermochemical cure model for predicting temperature and degree of cure profiles in curing phenolic parts was developed, validated and refined over several years. The model supports optimization of cure cycles and allows input of properties based upon the types of material and the process by which these materials are used to make nozzle components. The model has been refined to use sophisticated computer graphics to demonstrate the changes in temperature and degree of cure during the curing process.
\end{abstract}

The effort discussed in the paper will be the conversion from an outdated solid modeling input program and SINDA analysis code to an integrated solid modeling and analysis package (I-DEAS solid model and TMG). Also discussed will be the incorporation of updated material properties obtained during full scale curing tests into the cure models and the results for all the RSRM nozzle rings.

\section{INTRODUCTION}

Historically the model has been used to optimize cure cycles and to evaluate the effects of discrepant cure cycles on a part's temperature and cure response. This model was utilized to a great extent during the Reusable Solid Rocket Motor (RSRM) throat pocketing erosion investigation efforts. The intent of the cure modeling effort was to determine if the current cure cycle for the RSRM throat ring would provide adequate cure within current specifications. Finite element models of the nozzle ring cross-sectional geometry were generated with the I-DEAS software package and then analyzed using the TMG thermal generator analysis computer code. Validation of the model with thermocouple data from full scale parts was possible due to this effort. Material properties in the model were also updated as a result of lessons learned during the nozzle erosion investigation.

\section{BACKGROUND}

The model was originally developed using the System Improved Numerical Differencing Analyzer, SINDA heat transfer program as a basis.

Considerable effort was required to develop the user programmed subroutines to model other property changes which occur during cure. The model includes sub-routines for heat transfer total heat, thermochemical reactions and degree of cure.

The exothermic heat generation rate, $\dot{\boldsymbol{\theta}}_{\text {exo }}$ is expressed by the following:

$\dot{\emptyset}_{\mathrm{exo}}=\mathrm{m}_{\mathrm{resin}} \Delta \mathrm{H}_{\mathrm{rxn}} \delta \alpha \delta \mathrm{t}$

Where $\delta \alpha / \delta \mathrm{t}$ is the phenolic resin or cure reaction rate, $\mathrm{m}_{\mathrm{resin}}$ is the resin mass, and $\Delta \mathrm{H}_{\mathrm{rxn}}$ is the heat of reaction. During the cure of phenolics a chemical reaction occurs causing an exotherm within the part. This exotherm is seen in the thermocouple data when the internal temperatures in the part surpass the temperature of the boundary. The reaction rate for a chemical reaction with an Arrhenius temperature dependence is as follows:

$$
\begin{aligned}
& \mathrm{d} \alpha / \mathrm{dt}=\mathrm{ke}^{-\mathrm{E} / \mathrm{RT}}(1-\alpha) \\
& \text { where, }
\end{aligned}
$$

$\mathrm{d} \alpha / \mathrm{dt}=$ reaction rate, $\mathrm{lbm} / \mathrm{hr}$

$\mathrm{k}=$ frequency factor, $\mathrm{lbm} / \mathrm{hr}$

$\mathrm{E}=$ activation energy, Btu-lb-mole

$\mathrm{R}=$ gas constant $(1.987 \mathrm{Btu} / \mathrm{lb}-$ mole $\operatorname{deg} \mathrm{R})$

$\mathrm{T}=$ temperature, degree $\mathbf{R}$

The values for resin kinetics, i.e. activation energy, frequency factor and heat of reaction are determined from Differential Scanning Calorimetry (DSC) testing. A $35 \%$ resin mass fraction was assumed for the carbon phenolic prepreg. The Activation Energy defines the threshold temperature at which the part begins to exotherm, the Frequency Factor determines the rate of reaction and the heat of reaction determines the magnitude of the reaction.

In order to accurately predict the exothermic and viscous effects which occur during cure, it was necessary to use a two series reaction primarily for 
the exothermic phenomena in parallel with another single reaction to enhance the viscosity model.

$$
\begin{array}{ll}
\text { 1) Resin } \rightarrow \alpha \rightarrow \beta & \text { Series } \\
\text { 2) Resin } \rightarrow \delta & \text { Parallel }
\end{array}
$$

The equation for total heat dictates the amount of exotherm which occurs in the part once the threshold temperature has been reached.

The equation for total heat is as follows:

$\mathrm{Q}_{\text {total }}=\mathrm{Q}_{\alpha}{ }^{*} \mathrm{~d} \alpha / \mathrm{dt}+\mathrm{Q}_{\beta}{ }^{*} \mathrm{~d} \beta / \mathrm{dt}$

SINDA model grids were generated using SINGEN and the material orientation; cross-ply and with-ply properties were determined by hand. The new TMG code uses the I-DEAS solid modeling to define finite elements and the material orientation input determines the material direction, see figure 2 . The run times for analysis have been reduced from $30-45$ minutes to less than 1 minute. Figure 5 shows the comparison of the SINDA and TMG results for the RSRM throat ring.

\section{OBJECTIVES OF RECENT EFFORT}

All nozzle ring models required updates to incorporate updated material properties obtained during UUEC efforts. Also all nozzle rings needed to be checked to ensure the current configuration is being used. First and second wrap cure models for all RSRM nozzle rings using, I-DEAS and the Thermal Model Generator node for I-DEAS were created, see figure 1 .

\section{FIGURE 1. RSRM Nozzle Rings}

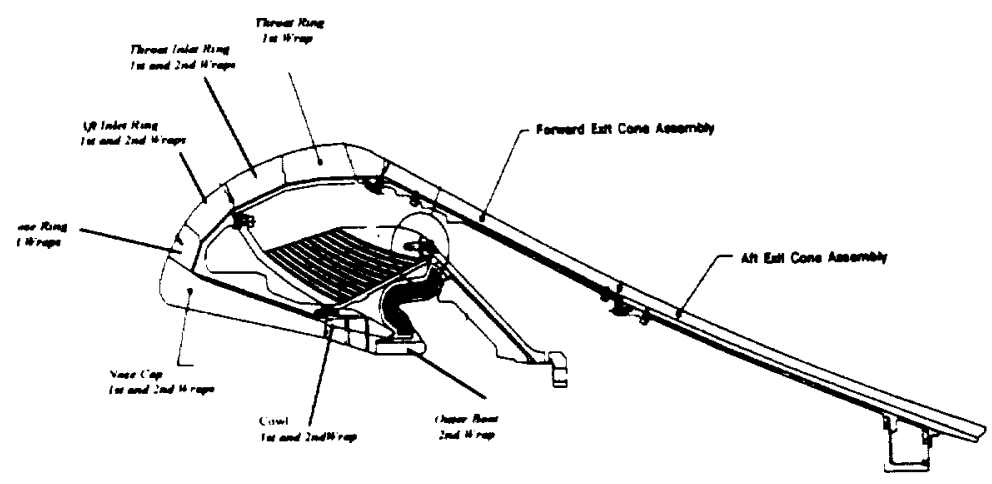

\section{DEGREE OF CURE MODELING (NEW MODEL)}

The new model uses I-DEAS Solid Modeling; a three dimensional model of the part with geometry input, material properties and three dimensional mesh generator. Three dimensional mesh thermal model generator; TMG is a thermal modeling and analysis tool using a geometry-based finite difference modeling approach. Considerable effort was required to develop the user programmed subroutines to model property changes which occur during cure. The TMG model includes subroutines for thermochemical reactions and degree of cure. The model post process capability provides output of temperature and degree of cure versus time and position and displays the thermal output in movie style, see figures 3 and 4.

\section{FIGURE 2. FE Model and Material Orientation}

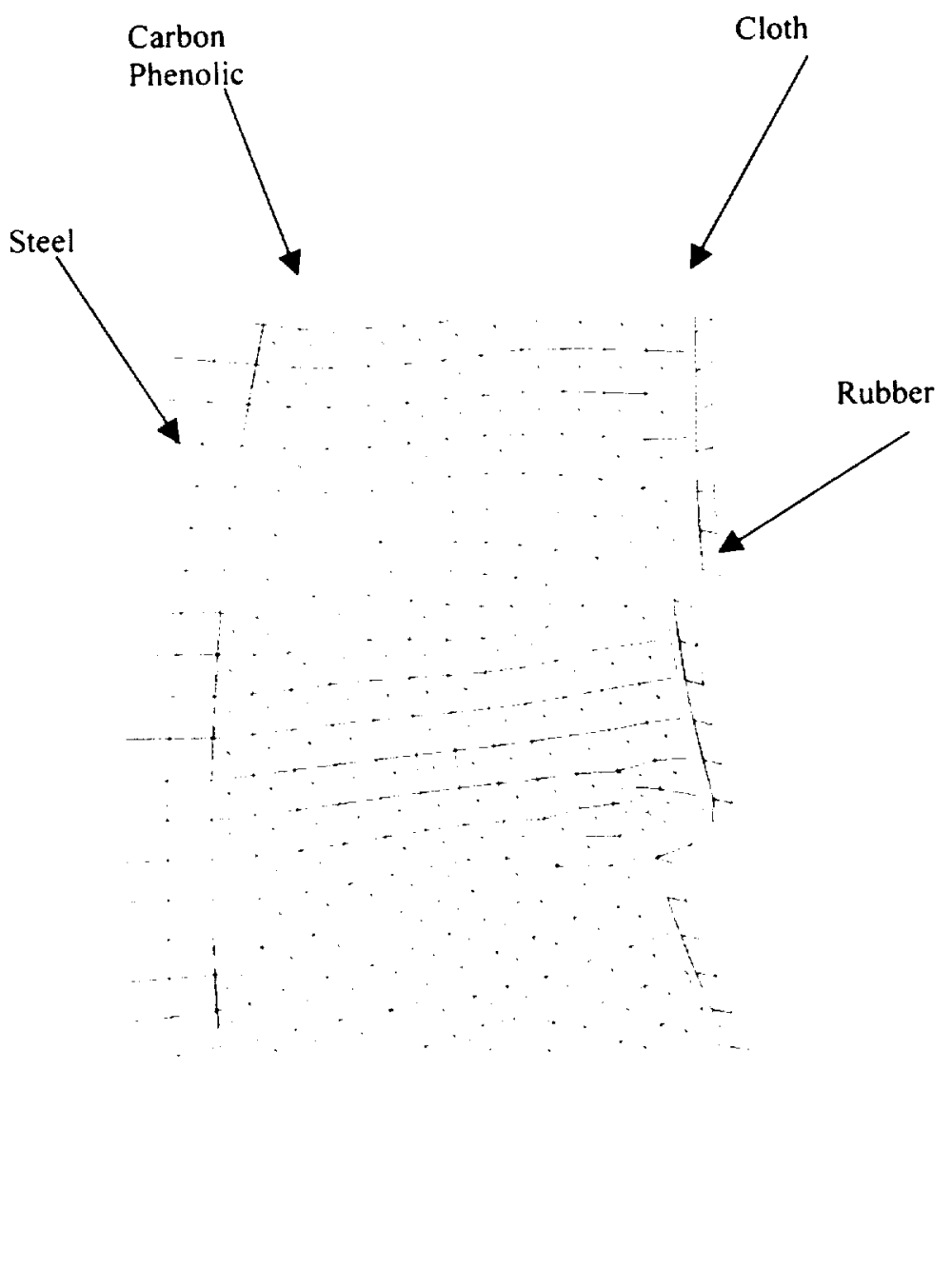


FIGLRE 3. Post process

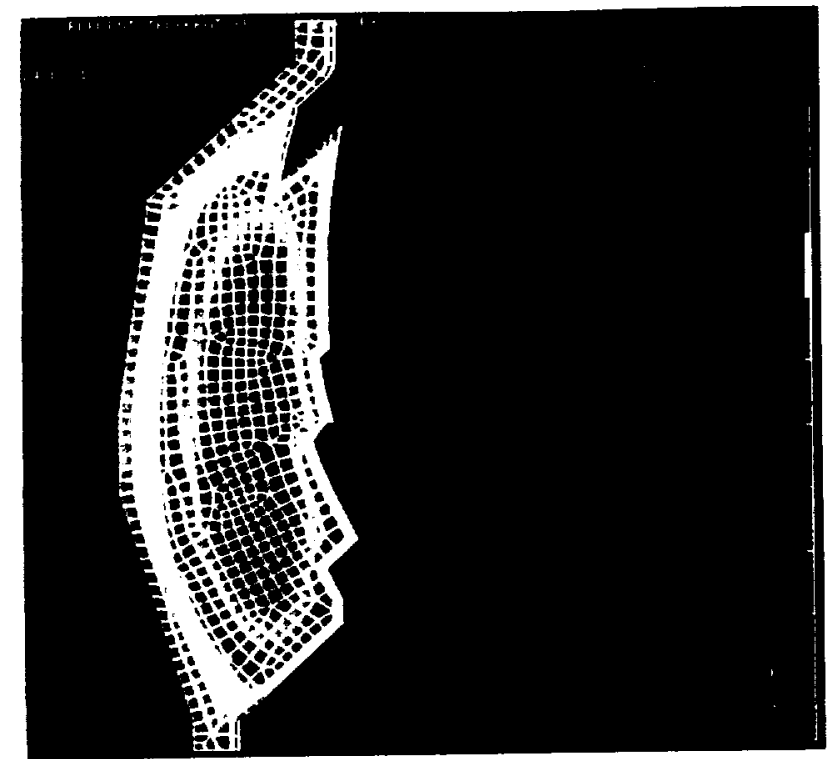

FIGilRe 4. Post Process

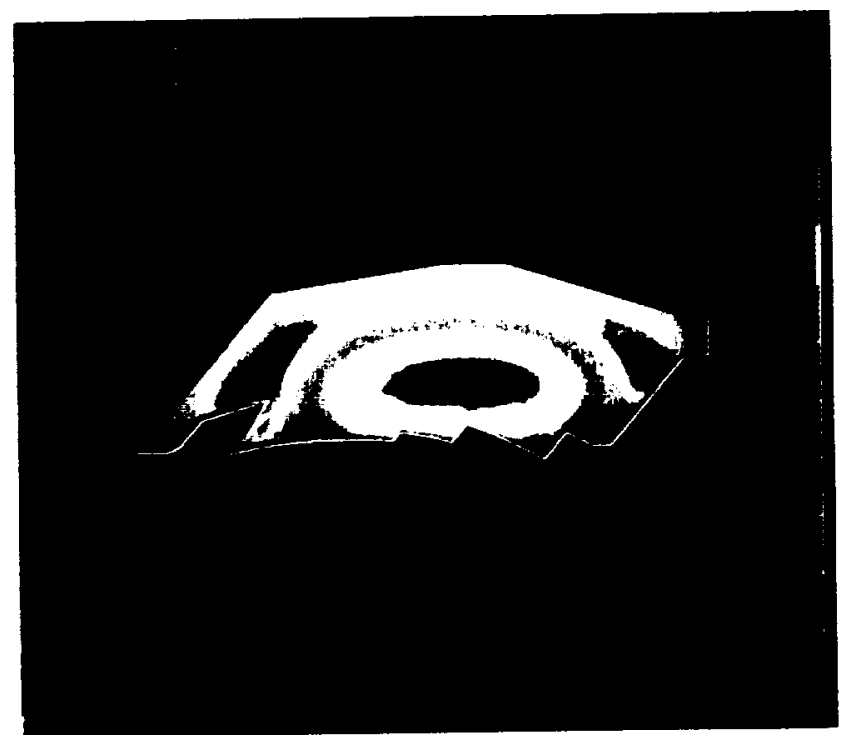

MODEL DEVELOPMENT AND

\section{VERIFICATION (VIX 4926)}

Initially bitues of conductivity for cured carbon phenolic were used in the model. these values were djusic: : retlect propres properties by matching

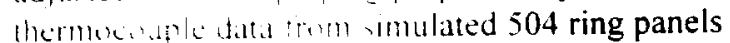
mutrumented and allud it WSFC. Resin kinetics and

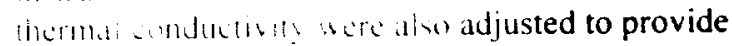
better wrotation bs matching the thermocouple data. comparion at actull and predicted thermocouple data for each panel was done to ensure reliability of model. During the Nozzle Throat Ring erosion investigation a number of full scale throat rings were instrumented prior to cure. This provided a unique opportunity to validate the cure model against full scale data. Figures 6 through 8 show some examples of the excellent correlation achieved between predicted and actual thermocouple data for the throat ring. forward nose ring and aft exit cone first wrap.

Figure 5. Comparison of SINDA and TMG

1et Wrap Throut ring

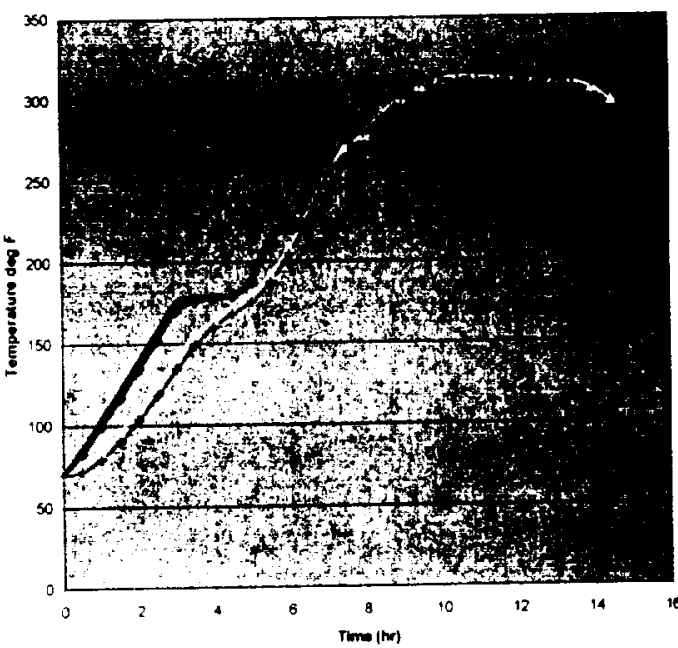

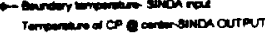

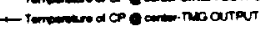

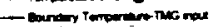

FIGURE 6. Comparison of Predicted and Actual temperature

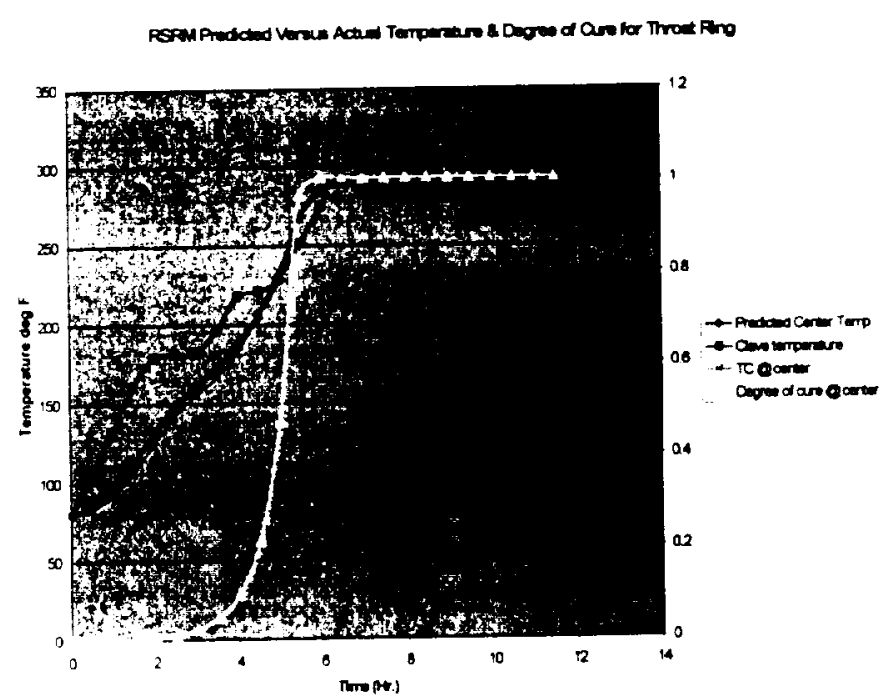


FIGURE 7. Comparison of Predicted and Actual temperature

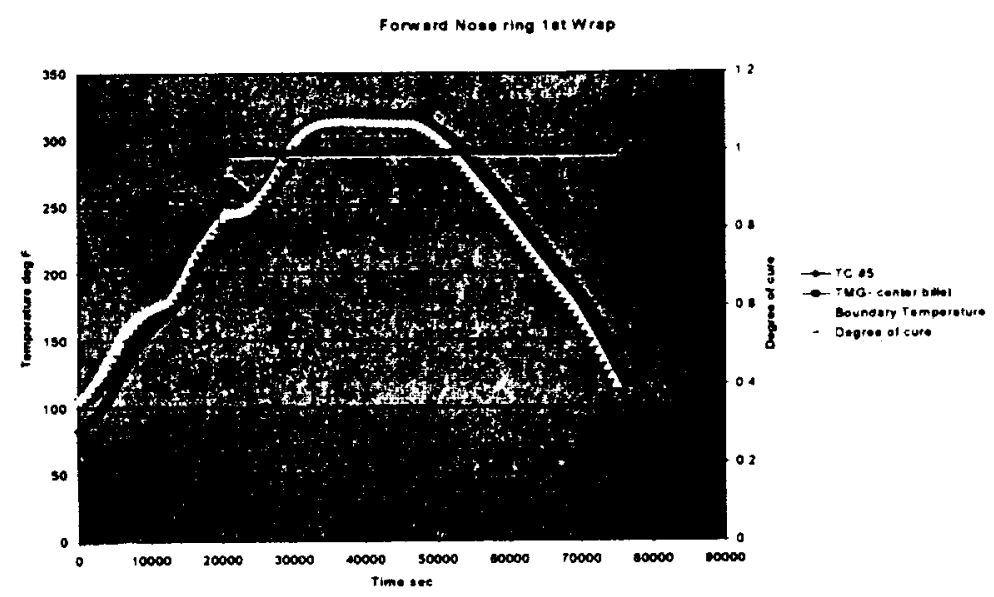

FIGURE 8. Comparison of Predicted and Actual Temperature

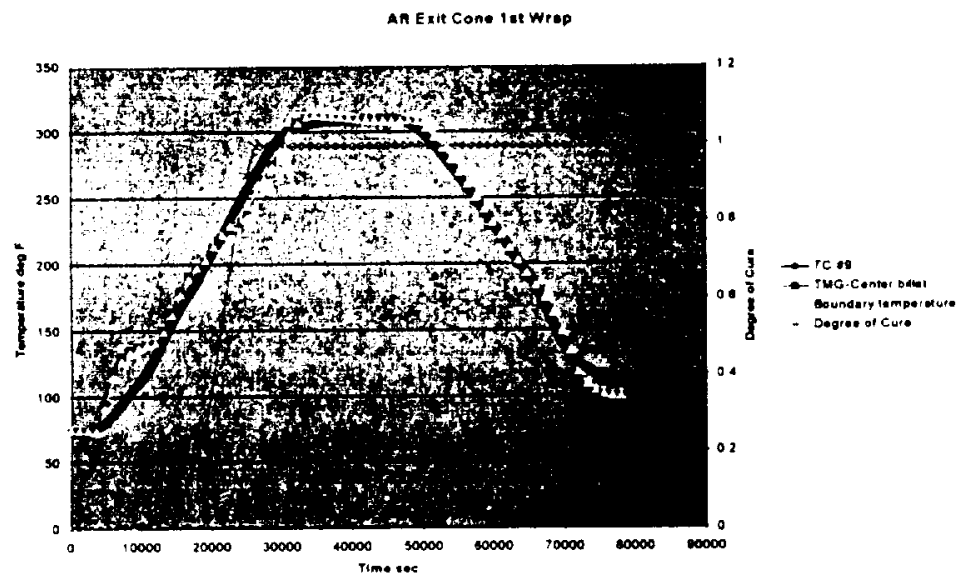

The most common cure model uses are assisting in cure cycle selection for new materials and part configurations, determining state of cure should an anomaly occur, providing temperature deviation of part should an anomaly occur and finally to study effects of material properties on curing such as the resin content and resin advancement. It's important to understand that the cure model is used only as an aide in the disposition process and has never been used as the only decision maker. During D.R. (Discrepancy Report) disposition tag end and X-ray data is used to substantiate cure analysis results. The model has been used to help evaluate several full scale UUEC rings, 60K, MNASA insulation and recent MNASA cure discrepancies.

\section{REFERENCES}

1. M. A. Letson, R. C. Bunker \& R.G. Clinton, "Process Modeling for Carbon Phenolic Nozzle Materials," AIAA 92-3299.

2. D.W. Clark, "RSRM Spacer Augmented cure Analysis," ED63(46-97)

3. M. A. Letson, "A Study of the Sensitivity of RSRM Nozzle Ring Cure Behavior to Material and Cure Cycle Variability" JANNAF 98

\section{RESULTS AND CONCLUSIONS}

The sensible approach to upgrade the cure model for RSRM nozzle rings was to recreate all of the models in IDEAS based on current drawings and material properties. The linking capabilities within IDEAS allows automatic updating of existing models based on design changes when the Master Model is updated. 